\title{
BRONCHOALVEOLAR LAVAGE STUDY IN PATIENTS OF SUSPECTED LUNG CANCER
}

\author{
Chingakham Debeshwar Singh1, P. Wilubuibou², Thounaojam Amusana Singh ${ }^{3}$
}

${ }^{1}$ Associate Professor, Department of Respiratory Medicine, JNIMS, Imphal, Manipur, India.

${ }^{2}$ Assistant Professor, Department of Respiratory Medicine, JNIMS, Imphal, Manipur, India.

3 Senior Resident, Department of Respiratory Medicine, JNIMS, Imphal, Manipur, India.

ABSTRACT
BACKGROUND
Bronchoalveolar lavage study in Bronchoscopy is done routinely during Bronchoscopy in patients suspected of lung cancer.
The aim of the study was to find out the importance of this procedure in detecting lung cancer including the co-existence of
other diseases like Tuberculosis in suspicion of lung cancer.

\section{MATERIALS AND METHODS}

It was a descriptive study of Bronchoalveolar Lavage (BAL) studies done in lung cancer suspects with negative sputum smear for Acid Fast Bacilli, presented at the Department of Respiratory Medicine of a Medical College Hospital in a remote area. The results of BAL reports recorded for all the 93 patients who presented to the department from December 2016 to May 2017 were studied. All the BAL samples were subjected to Cytology study and CBNAAT-TB (Cartridge Based Nucleic Acid Amplification Test for TB).

\section{RESULTS}

Out of the 93 BAL reports of lung cancer suspects, 21 were found to be having lung cancer alone and 3 were found to be having lung cancer with Pulmonary Tuberculosis and 2 were found to be having Pulmonary Tuberculosis.

\section{CONCLUSION}

BAL study is an important tool in detection of Lung cancer in India. It is useful for detection of Tuberculosis in patients with negative sputum smear for Acid Fast Bacilli. Our study further shows that patients presenting with symptoms and radiological findings suggestive of lung cancer are also found to be having coexisting Tuberculosis. It also reveals that TB should be a differential diagnosis of lung cancer and possibility of coexistence of both diseases should always be considered in our country.

\section{KEY WORDS}

Bronchoscopy, Bronchoalveolar Lavage, Lung Cancer, Tuberculosis.

HOW TO CITE THIS ARTICLE: Singh CD, Wilubuibou P, Singh TA. Bronchoalveolar lavage study in patients of suspected lung cancer. J. Evolution Med. Dent. Sci. 2018;7(41):4409-4410, DOI: 10.14260/jemds/2018/984

\section{BACKGROUND}

Bronchoscopy is indicated in patients having suspected lung cancer, having chronic undiagnosed cough, haemoptysis, focal unexplained atelectasis and post-obstructive pneumonia, undiagnosed pleural effusions, obvious mass on chest x-ray or CT-scan of thorax and localised wheeze. ${ }^{1}$

Bronchoalveolar Lavage (BAL) is routinely done in a procedure of Bronchoscopy and subjected to cytology study, other analysis in diagnosis of infections and other noninfective studies. In India, in a general set-up the BAL fluid should be subjected to ZN stain and CBNAAT-TB if available must also be done for detection of Tuberculosis.

\section{MATERIALS AND METHODS}

It was a descriptive study. All the 93 patients suspected to be having lung cancer with ZN stain for AFB negative were subjected to Bronchoscopy and BAL study, during the period of December 2016 to June 2017, at the Department of

'Financial or Other Competing Interest': None.

Submission 12-09-2018, Peer Review 25-09-2018,

Acceptance 28-09-2018, Published 08-10-2018.

Corresponding Author:

Dr. Chingakham Debeshwar Singh,

Associate Professor,

Department of Respiratory Medicine,

JNIMS, Imphal, Manipur, India.

E-mail: debeshwar@gmail.com

DOI: $10.14260 /$ jemds $/ 2018 / 984$

\section{(c) (i) $\$$}

Respiratory Medicine of a new Medical College in a remote state of India. Alveolar contents are sampled during the procedure of Bronchoscopy. The tip of Bronchoscope was wedged at the desired bronchopulmonary segments and isotonic saline was instilled through the working channel of bronchoscope in $20-60 \mathrm{~mL}$ aliquots. A total volume of 100 and $300 \mathrm{~mL}$ divided in $3-5$ aliquots were instilled. After instillation of each aliquot, fluids were recovered by suction into sterile disposable collecting traps. Normally, $40-70 \%$ of instillation volume is recovered as per guidelines. ${ }^{1,2,3}$ BAL aspiration provides material of a larger area of the bronchial mucosa. 4

The BAL fluid was sent to Departments of Microbiology and Pathology in the same hospital and processed within 1 - 4 hours of collection. In the Department of Pathology, Cytology study was conducted and CBNAAT-TB was performed in the Department of Microbiology for detection of Tuberculosis.

Supplementation of oxygen through nasal prong was provided though the procedure to patients with COPD and pulmonary fibrosis with $\mathrm{SaO} 2$ less than $90 \%$ as per guidelines. ${ }^{3}$

\section{RESULTS}

$74 \%$ lung cancer suspected patients presented with lung consolidation, $9.6 \%$ presented with collapse of lung, $5 \%$ with ground glass opacities, $4 \%$ with pleural effusion, $3 \%$ with thick walled cavities and $3 \%$ with haemoptysis. 


\begin{tabular}{|c|c|}
\hline Clinical Presentations of Patients & Number \\
\hline Air space consolidations & $69(74 \%)$ \\
\hline Collapsed lung on one side & $9(9.6 \%)$ \\
\hline Ground glass opacities & $5(5 \%)$ \\
\hline Undiagnosed pleural effusions & $4(4 \%)$ \\
\hline Cavities & $3(3 \%)$ \\
\hline Haemoptysis & $3(3 \%)$ \\
\hline \multicolumn{2}{|c|}{ Table 1. Clinical presentations of Lung Cancer suspected } \\
Patients \\
\hline
\end{tabular}

Out of the 93 BAL samples studied 21 were found to be having lung cancer alone, 3 were having lung cancer with Tuberculosis and 2 were having Tuberculosis alone, remaining 57 had other findings.

\begin{tabular}{|c|c|}
\hline Total Patients & $\mathbf{9 3}$ \\
\hline Lung cancer only in BAL & $21(23 \%)$ \\
\hline Lung cancer with TB in BAL & $3(3 \%)$ \\
\hline TB only in BAL & $2(2 \%)$ \\
\hline Table 2. Results of BAL Study showing Detection of Lung \\
Cancer and Tuberculosis \\
\hline
\end{tabular}

\begin{tabular}{|c|c|c|c|c|c|}
\hline \multirow[b]{2}{*}{ Age } & \multicolumn{5}{|c|}{ Results } \\
\hline & 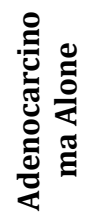 & 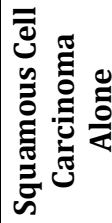 & 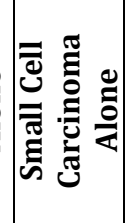 & 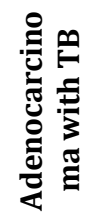 & 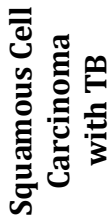 \\
\hline $\begin{array}{l}55-65 \\
\text { years }\end{array}$ & 1 & 0 & 0 & 1 & 0 \\
\hline $\begin{array}{l}66-75 \\
\text { years }\end{array}$ & 5 & 4 & 2 & 1 & 1 \\
\hline $\begin{array}{l}76-85 \\
\text { years }\end{array}$ & 4 & 4 & 0 & 0 & 0 \\
\hline Total & 10 & 8 & 2 & 2 & 1 \\
\hline
\end{tabular}

\begin{tabular}{|c|c|}
\hline BAL Reports showing Lung Cancer & Number \\
\hline Total Lung cancer in BAL & 24 \\
\hline Lung cancer with TB in BAL & 3 \\
\hline \multicolumn{2}{|c|}{ Table 4. Lung Cancer with TB among Total Lung Cancer } \\
Detected
\end{tabular}

\section{DISCUSSION}

BAL study is very helpful in detection of lung cancer in patients having symptoms and radiological findings suggestive of lung malignancy. This study indicates that a safer procedure like this must be carried out in bronchoscopy, subjecting to cytology study and CBNAAT-TB in our country. The differential diagnosis of TB should always be considered either as isolated illness or co-morbidity. The presence of TB can occur as the preceding illness, as occurrence of lung cancer as a result of pulmonary fibrosis leading to genetic damage happens. ${ }^{4}$ In our study, diagnostic yield of the procedure in lung cancer in patients with clinical suspicion for lung malignancy was $25 \%$. Bronchoalveolar studies have been reported to be very useful in diagnosis of adenocarcinoma and tumours with lymphangitic or lepidic growth. ${ }^{5}$ A yield of $35 \%$ - $69 \%$ have been observed in one study by Semenzato G and Poletti V. 5 The overall diagnostic yield was reported in a study ranging from 35 to $69 \% .^{6}$ In another study, highest yields were seen in adenocarcinoma (59.2 percent) and alveolar cell lung cancer ( 80 percent). ${ }^{7}$ BAL was positive for malignant cells in 14 of the 30 patients $(46.7 \%)$ in the study by Wongsurakiat P. 8 The various clinical presentations in this study were lung consolidation, ground glass opacities similar to a study by Cazzato $\mathrm{S}$ et al. ${ }^{9}$

$1.9 \%$ of lung cancer patients were found to be having TB in one study, ${ }^{10}$ although in our study such a co-existence was $12.5 \%$, although our study detected TB only in BAL study in sputum smear negative for AFB.

\section{CONCLUSION}

It is observed that BAL is a valuable diagnostic tool in detecting primary, pulmonary malignant neoplasms. In a country like India, BAL should always be subjected to CBNAAT-TB study also, as TB can mimic lung cancer and coexist with pulmonary malignancy, although such coexistence is rare.

\section{REFERENCES}

[1] Ernest A, Herth FJF. Introduction to bronchoscopy. Chapter - 8. Flexible bronchoscopy: indications, contraindications and consent. $2^{\text {nd }}$ edn. Cambridge University Press 2017: p. 95.

[2] Collins AM, Rylance J, Wootton DG, et al. Bronchoalveolar Lavage (BAL) for research: obtaining adequate sample yield. J Vis Exp 2014;85: e4345.

[3] Technical recommendations and guidelines for bronchoalveolar lavage (BAL). Report of the European Society for Pneumology Task Group. Eur Respir 1989;2(6):561-85.

[4] Franke KJ, Nilius G, Rühle KH. Bronchoscopic diagnosis of peripheral pulmonary foci. Dtsch Med Wochenschr 2006;131(40): 2229-33.

[5] Poletti V, Poletti G, Murer B, et al. Bronchoalveolar lavage in malignancy. Semin Respir Crit Care Med 2007;28(5):534-45.

[6] Semenzato G, Poletti V. Bronchoalveolar lavage in lung cancer. Respiration 1992;59 Suppl 1:44-6.

[7] Pirozynski M. Bronchoalveolar lavage in the diagnosis of peripheral, primary lung cancer. Chest 1992;102(2):372-4.

[8] Wongsurakiat P, Wongbunnate S, Dejsomritrutai W, et al. Diagnostic value of bronchoalveolar lavage and postbronchoscopic sputum cytology in peripheral lung cancer. Respirology 1998;3(2):131-7.

[9] Cazzato S, Zompatori M, Burzi $M$, et al. Bronchoalveolar lavage and transbronchial lung biopsy in alveolar and/or ground-glass opacification. Monaldi Arch Chest Dis 1999;54(2):115-9.

[10] Tamura A, Hebisawa A, Hayashi K, et al. Lung cancer in patients who had received thoracoplasty for pulmonary tuberculosis. Jpn J Clin Oncol 1999;29(11):541-5. 